\section{New Short Courses To Be Offered on Materials Characterization and Topics Complementing MRS Meetings}

The goals of the MRS Short Course Program are described elsewhere in this issue (See "MRS Committees Announce 1987 Priorities.") As mentioned in that article, several technical themes are being pursued in the development of the short course program. The themes that have formed the foundation of the program include courses in (1) materials preparation and fabrication, (2) techniques of materials processing and experimentation, (3) utilization of materials, and (4) materials characterization. The program offered at the 1987 MRS Spring Meeting includes many courses under these categories. While there is interest in quality courses which fit the general themes, courses are also given in other areas of special interest to MRS.

The Education Committee has identified a special need for courses in materials characterization, and it is one area that is being actively pursued. It is believed that this represents a unique area of materials science instruction which is not being addressed coherently by other organizations involved with short course educational programs. At the 1985 MRS Fall Meeting the following courses were included: "Surface and Thin Film Analysis," "Reflection
High Energy Electron Diffraction," and "Deep Level Transient Spectroscopy." In 1986 these courses were successfully repeated and two new courses, "Modern Materials Analysis Techniques" and "Transmission and Analytical Electron Microscopy," were added. At the upcoming 1987 Fall MRS Meeting the following new courses will be presented: "Scanning Electron Microscopy," "Scanning Tunneling Microscopy," "Atom Probe Field Ion Microscopy," and "Nuclear Magnetic Resonance."

A complement to courses on the techniques in materials characterization is the topical area of characterization of specific technological materials. Courses which have been presented in this area include: "Properties of Films and Coatings," "Electronic Properties of Amorphous Semiconductors," and "Ceramic and Metal Matrix Composites." For the 1987 Fall Meeting program it is planned to add "Characterization of Powders and Porous Materials."

The area of advanced materials is being addressed. No separate theme is identified because many courses dealing with advanced materials are already identified as being included in the materials preparation, processing, or fabrication themes. These include courses such as "Films and Coatings for Science and Technology," "Ion Beam Processes for Materials Modification," and "Sol-Gel Processing of Glass." Plans are to add a new course on "Rapidly Solidified Materials."
In addition to the major technical themes, new courses are offered which complement the MRS meeting symposia. Examples are "Fractals in Materials Science," "Rapid Thermal Processing," and "Plasma Etching," to name a few. New courses which will complement symposium topics are in the planning phase and will address the fundamentals of polymers, photochemical processing, and thermal plasma processing.

The MRS Short Course Program will continue to expand the portfolio of courses available to the materials science community. Although only a selected group of courses can be presented at any one MRS meeting, every effort will be made to continue to offer not only the most popular MRS courses but also new courses on important topics, which are currently not available in the short course portfolios of other organizations.

The On-Site Short Course Program is available to the materials science and engineering community if a course of particular interest to an organization is not included with the next program offering at an MRS meeting. The entire portfolio of courses available for On-Site presentation is listed elsewhere in this issue.

Alton D. Romig, Jr. Education Committee Cochair

Vivienne Harwood Mattox MRS Short Course Manager

BRING THE EXPERTS TO YOU . . .

ON-SITE SHORT COURSES conducted at your facilities or a nearby site

The best way to keep your staff on top of their fields is through an on-going program of continuing education. One of the most efficient, cost-effective methods is to bring experts to your geographical location so that they can teach the latest techniques, discuss the newest research, and talk to your staff about the actual problems that they face daily.

The economic savings of On-Site programs are considerable, both in terms of time and budget. There are no travel fees or hotel costs for your staff, and attendees lose minimal time from their work.

MRS On-Site courses will be adapted to the specific needs of the sponsoring organization and the management will have an opportunity to interact with the instructor to discuss the course emphasis. Written requests from organizations will be handled on a first-come, first-served basis. For further details of courses which are available, prices and other information, write or call:

\author{
Vivienne Harwood Mattox, MRS Short Course Manager \\ 440 Live Oak Loop, Albuquerque, NM 87122; (505) 294-9532
}

